\title{
Light induced silver and copper plating on silver screen-printed contacts of silicon solar cells
}

\author{
S. TUTASHKONKO* ${ }^{* 1,2}$, A. KAMINSKI-CACHOPO ${ }^{1}$, C. BOULORD ${ }^{1}$, R. ARS ${ }^{2}$, V. AIMEZ ${ }^{2}$, \\ and M. LEMITI ${ }^{1}$
}

${ }^{1}$ Institut des Nanotechnologies de Lyon INL-UMR5270, Universite de Lyon, CNRS, INSA de Lyon, Villeurbanne, F-69621, France

${ }^{2}$ CRN2, Universite de Sherbrooke Sherbrooke, Quebec, Canada J1K 2R1

[OPTO-ELECTRONICS REVIEW 19(3), 301-306 (2011) ]

In the paper the following erros are found:

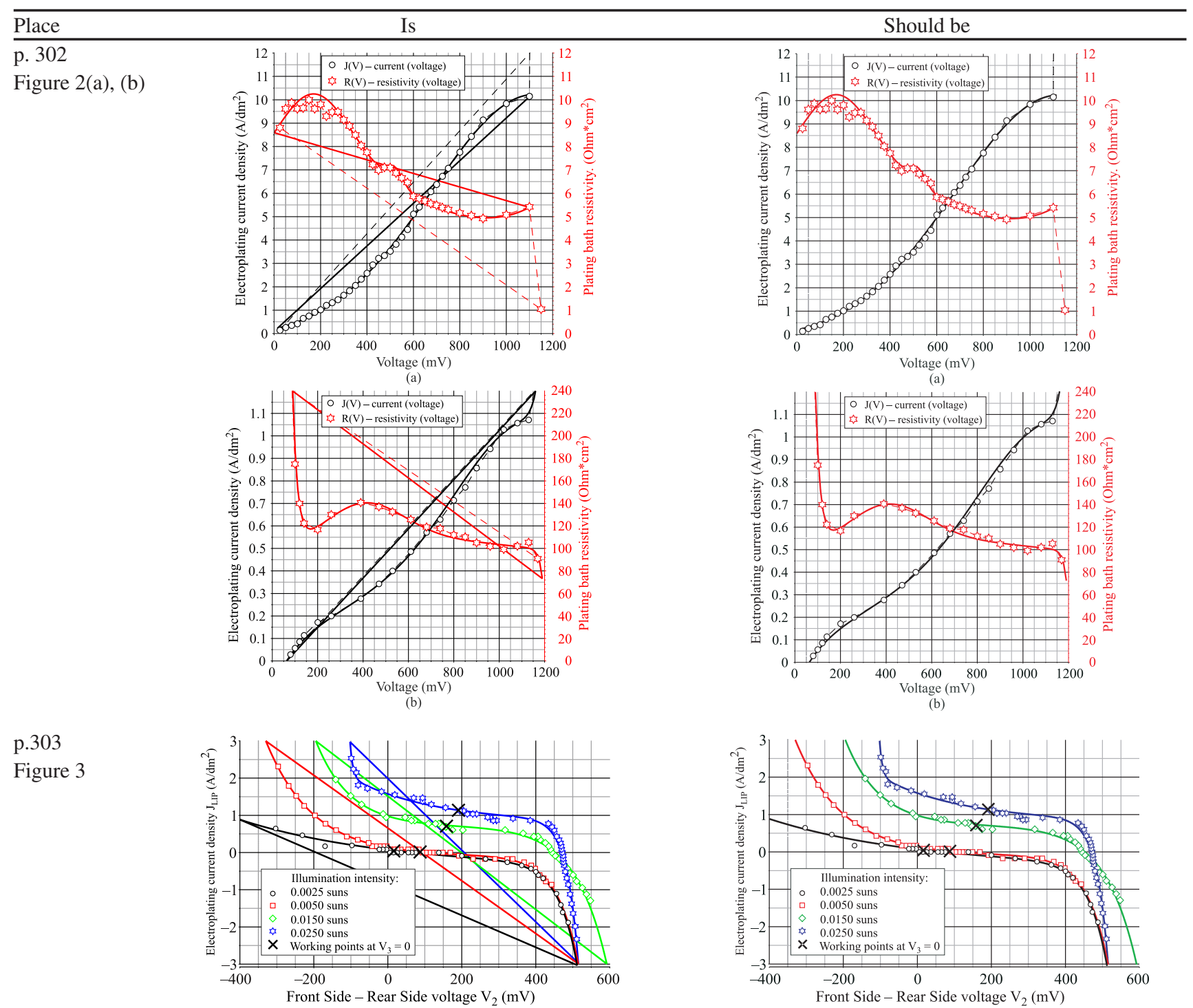




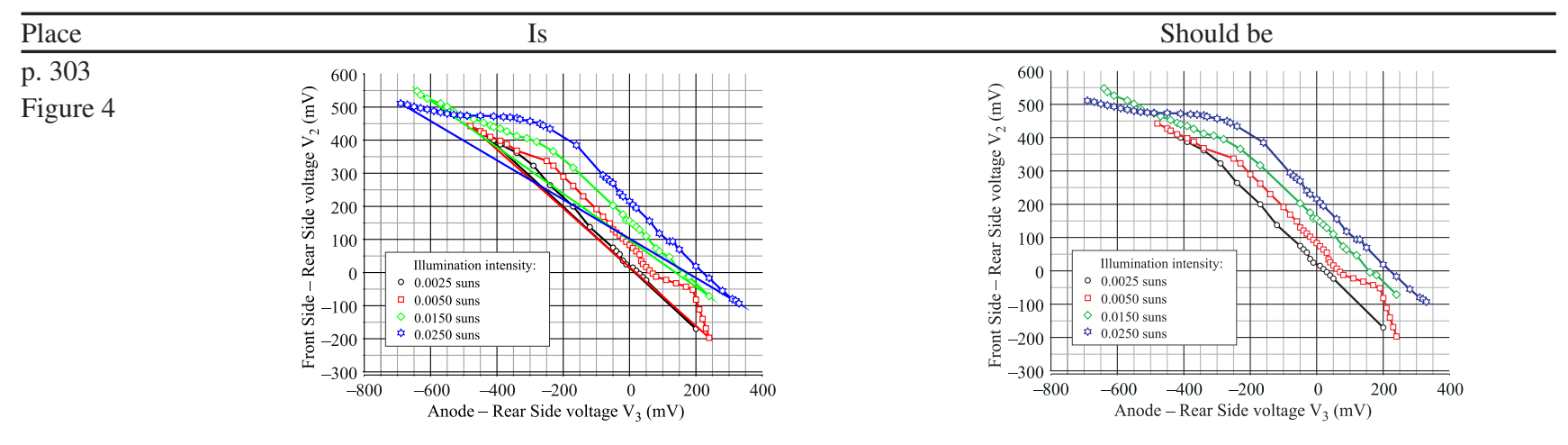

p. 304

Figure 5

p. 304

Figure 6

p. 305

Figure 7

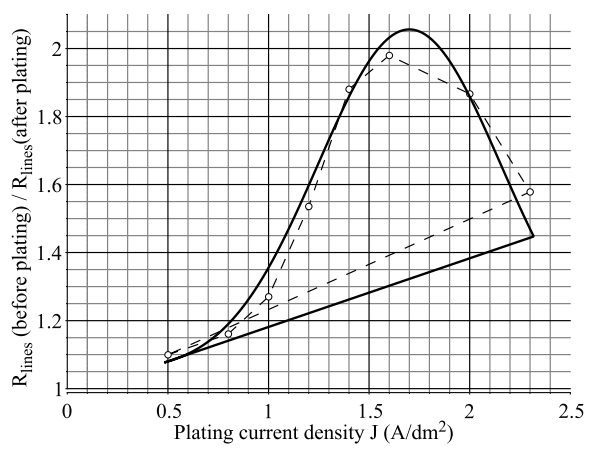

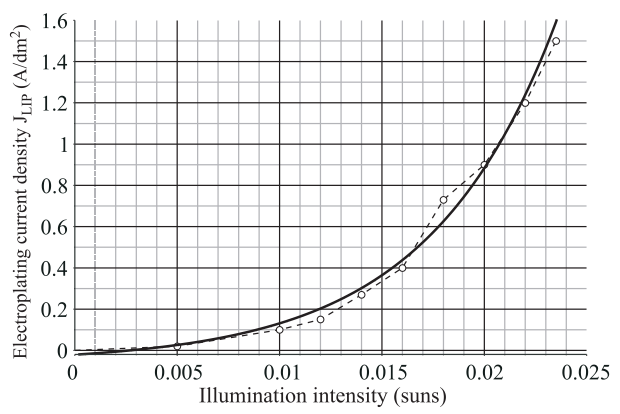
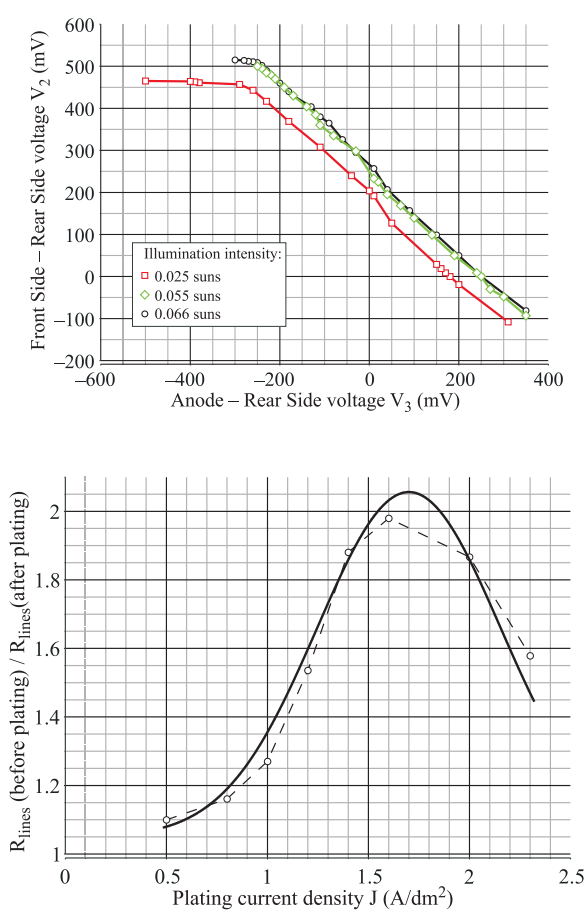